\title{
Measuring and modeling moisture environment in underground metro stations during commissioning stage: A case study
}

\begin{abstract}
Due to the humid underground environment, underground metro stations often have internal condensation issues, especially during the commissioning and initial operation phases, and these issues will have a negative impact on the equipment operation and building life. This study aims to solve the issue by 1) identifying common areas with condensation risks based on on-site measurements and numerical simulation methods, and 2) proposing effective dehumidification solutions for the moisture control of stations. By on-site investigating the characteristics of the station's moisture environment and numerical assessing the effects of two different dehumidification strategies, it has been found that 1) for Tianjin, during most times in summer, the air temperature of the station in the commissioning phase was maintained relatively stable, but with significantly changing humidity; 2) the relative humidity on the platforms was higher than $80 \%$ for almost $30 \%$ of the testing time, and the surface of the upper structure of platform doors having a high risk of condensation; 3) the dehumidification effect of industrial dehumidifiers was found to be better than that of increasing exhaust air volume. The authors hope that the research could aid the decision on dehumidification strategies and provide guidance for further moisture control in underground stations.
\end{abstract}

\section{Keywords}

metro stations, underground environment, moisture control, on-site measurement, numerical simulation, dehumidification 


\section{Practical Application}

This paper analysed the moisture environment of the underground metro stations in the commissioning phase and conducted a numerical approach to assess the condensation risk. Potential dehumidification solutions including increasing the exhaust air volume and using industrial dehumidifiers have been proposed, and their effects have been investigated and compared. The authors hope that this research can aid the decision on dehumidification strategies for facilities maintenance and provide a guidance to further moisture control in underground stations.

\section{Nomenclature}

\begin{tabular}{|clll|}
\hline Nomenclature & & \\
$C$ & heat capacity of air $\left(\mathrm{kJ} /{ }^{\circ} \mathrm{C}\right)$ & Greek symbols \\
$V$ & volume of the station $\left(\mathrm{m}^{3}\right)$ & $\rho$ & density $\left(\mathrm{kg} / \mathrm{m}^{3}\right)$ \\
$H$ & height $(\mathrm{m})$ & $\tau$ & time $(\mathrm{s})$ \\
$L$ & length $(\mathrm{m})$ & Abbreviations \\
$q$ & moisture gain $(\mathrm{kg} / \mathrm{h})$ & AGMs & automatic gate machines \\
$Q$ & heat transfer rate $(\mathrm{kW})$ & PSDs & platform screen doors \\
$T$ & temperature $\left({ }^{\circ} \mathrm{C}\right)$ & $\mathrm{RH}$ & relative humidity \\
$W$ & width $(\mathrm{m})$ & $\mathrm{Subscripts}$ \\
$w$ & humidity ratios $\left(\mathrm{kg}_{\text {water }} / \mathrm{kg}_{\text {dry air }}\right)$ & $\mathrm{a}$ & air \\
& & $\mathrm{d}$ & dew point \\
& & $\mathrm{s}$ & surface \\
\hline
\end{tabular}




\section{Introduction}

Metro transport is rapidly developing worldwide as a convenient and efficient means of public transport. With the flourishing development of metro networks in China, increasingly metro stations have been built in recent years. Specifically, there were 40 cities with established metro networks in China, and a total of 534 stations have been built nationwide in $2019 .{ }^{1}$ However, as the metro station is a special kind of transportation building built underground, the environment of the underground stations is usually humid because of the moisture in the soil and insufficient ventilation ${ }^{2}$. It has been reported that in Glasgow, UK, the air relative humidity in most local metro stations was between $70 \%$ and $80 \%$ all year round, with seasonal mean temperature ranged between $11.5{ }^{\circ} \mathrm{C}$ and $18.4{ }^{\circ} \mathrm{C}^{3}$, higher than that of commercial buildings.

The humid station environment would face moisture condensation occurring on the interior surface of the envelope and the external surface of equipment very often. The surface condensation not only affects the aesthetics of the envelope and equipment (see Figure 1), but also increases the risk of deterioration of envelope materials and short circuit of equipment. ${ }^{4}$ It is known that a long-term value of indoor relative humidity in excess of $75 \%$ could greatly affect the performance of electronic devices owing to their instability, resulting in unforeseen problems when used for emergencies. ${ }^{5}$ Moreover, extra moisture in the air would worsen the indoor air quality (IAQ) and lead to mould growth. Therefore, moisture control is essential to avoid these adverse effects and ensure the safe operation of stations. 


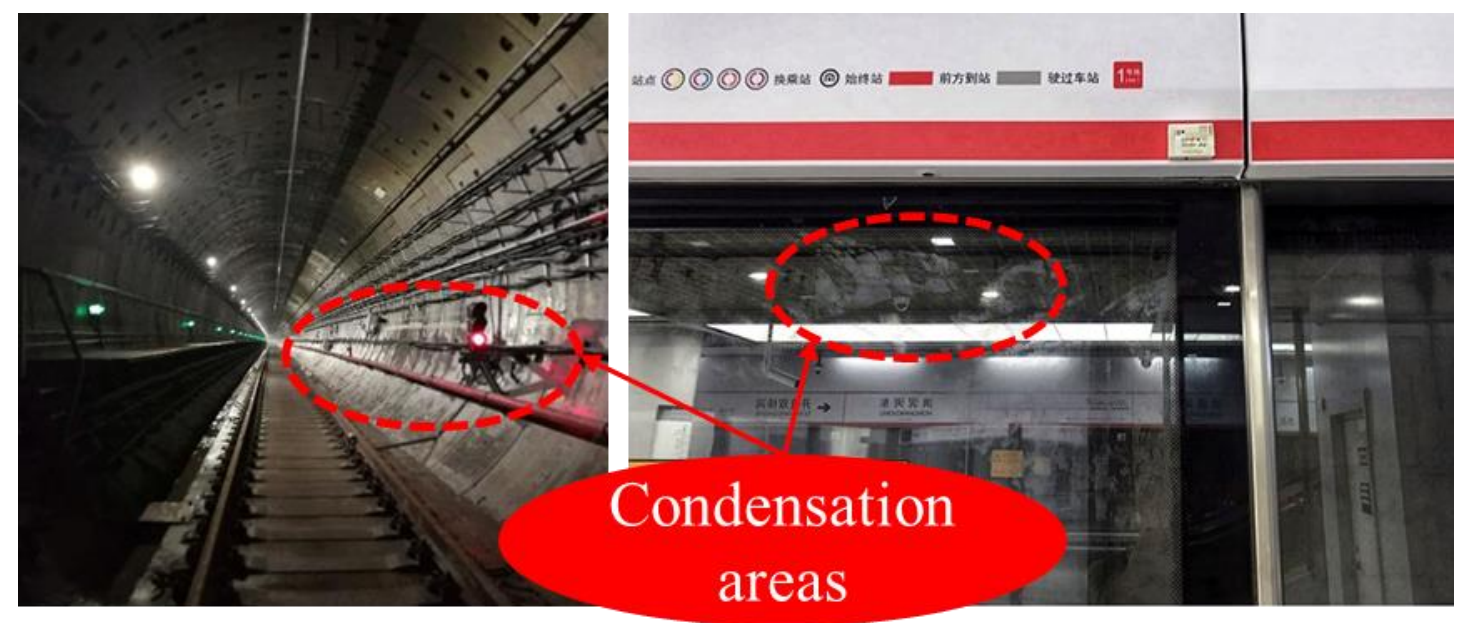

Figure 1. Condensation on tunnel walls and platform doors in an underground station.

Currently, numerous studies relevant to the environment of metro stations have focused on the control of thermal environment ${ }^{6-8}$ and $\mathrm{IAQ}^{9-11}$ for passengers in the operating stations. For example, different ventilation schemes (mixing ventilation, stratified air ventilation and air curtain ventilation) ${ }^{12,13}$ and platform doors (platform screen doors ${ }^{14}$, platform bailout doors ${ }^{15}$, and adjustable ventilation platform doors ${ }^{16,17}$ were proposed for the optimization design of the station's thermal environment. In addition, various techniques (ventilation fans, magnetic filters, small jet fans, artificial intelligent ventilation systems, hybrid filters, etc) ${ }^{18,19}$ have been developed to reduce the concentration of particulate matters in underground metro systems. However, limited studies have been reported for the moisture control of underground stations, although it has been found high humid and common exposure to the hazards caused by condensation. ${ }^{20}$ For metro stations during commissioning stage, especially, heat generation in the station is relatively low, comparing to operation stage. This is mainly because that there is no heat dissipated from passengers, operating equipment and train braking etc., giving lower air temperature and higher condensation risk. ${ }^{21}$ 
To investigate the condensation risk in underground stations, Wang $^{22}$ has conducted field measurements in one station in Nanjing, China, during the initial operation phase in summer. In the study, he identified that technical rooms were facing higher risk of condensation, due to the poor management of ventilation systems, and suggested adding thermal insulation and automatic air dampers to the ducts in ventilation systems. Some studies also analysed the moisture environment of underground buildings by field tests and proposed improved strategies such as using proper air exchange, insulation materials and liquid desiccant, ${ }^{23}$ but the effects of these strategies were rarely assessed in underground stations. Additionally, there were attempts on developing an integrated model based on image processing techniques and artificial intelligence to automate consistent moisture marks detection and numerical representation of distress in metro networks. ${ }^{24,25}$

Within this context, the aim of this paper is to analyse the indoor environmental characteristics and find the typical areas where condensation most likely occurs in the public areas (hall and platform) of underground stations by field measurements and numerical simulations, and propose suitable dehumidification solutions. The remainder of this paper is organized as follows. Section 2 provides a detailed description of the study methodologies. Section 3 describes the measurement and modelling results and analysis of the moisture condensation in different scenarios. Section 4 presents a thorough conclusion of the paper.

\section{Methodologies}

In this section, the holistic approach of the study is described in detail. Firstly, the 
condensation mechanism in the underground station is introduced and the criteria for evaluation moisture condensation are given. Secondly, the environment of the underground station is on-site measured and analyzed. Finally, the numerical models are developed and validated to analyze the risk of condensation under the design condition and the effect of dehumidification solutions.

\subsection{Condensation mechanism}

To better explore the moisture environment of public areas in the underground station during commissioning, an in-depth understanding of the heat and moisture balance of the station and the reason behind condensation are necessary. As the station is built under the ground, there is no solar radiation gained and the ground temperature is relatively stable. ${ }^{26}$ Moreover, the station is separated from the surrounding ground by a layer of silicate board and a layer of reinforced concrete structure, and there is a very limited exchange of heat and moisture between the ground and the station (as shown in Figure 2). ${ }^{27}$ Nevertheless, the moisture in the soil can still enter the station with the diffusion of tunnel air through the leakage of platform screen doors (PSDs). Thus, the environment of public areas can be humid and occur condensation with insufficient ventilation Figure 3 shows the heat/moisture gains for the public areas of the station. 


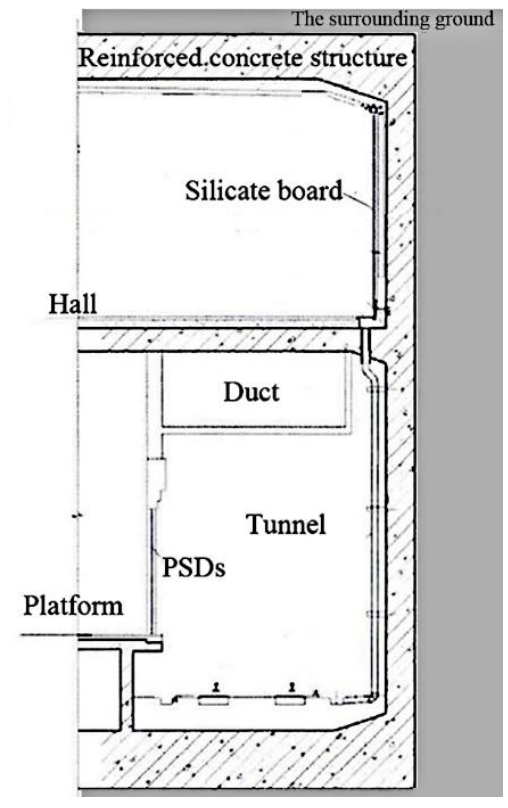

Figure 2. Schematic of underground station structure (half section).

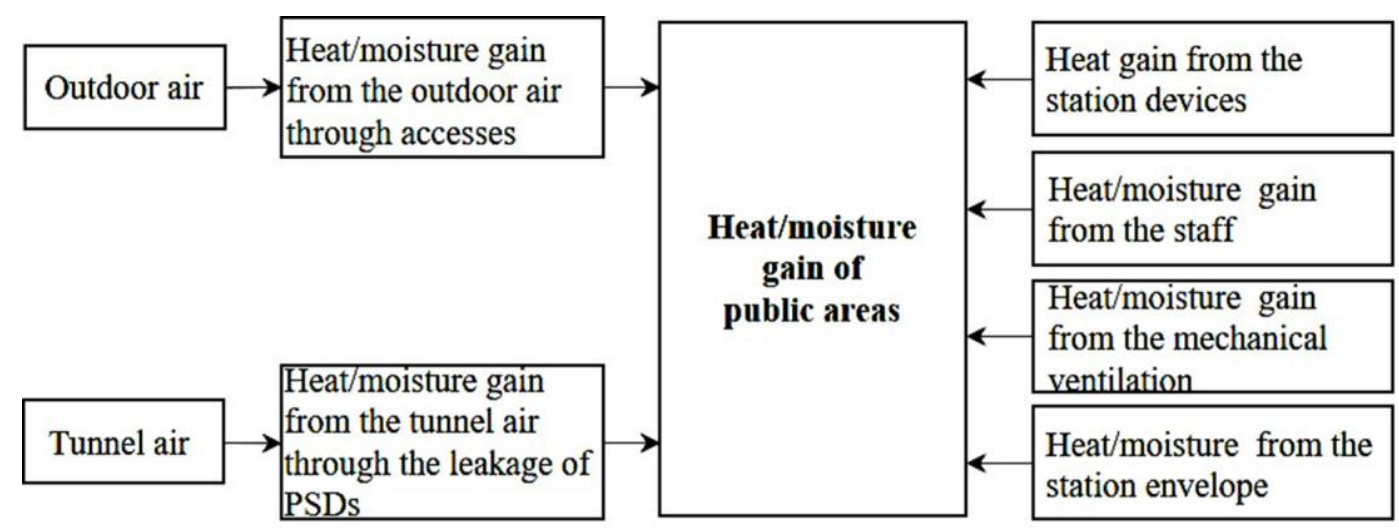

Figure 3. Schematic of heat/moisture gain for the public areas of an underground station during commissioning.

The heat gain of the station is composed of the heat gain from unorganized air infiltration comes from either outdoor or tunnel, heat dissipation of devices such as lamps and automatic gate machines (AGMs), heat dissipation of the personnel, heat gain from the mechanical ventilation air, and heat gain from the envelope. The composition of moisture gains is similar as the heat sources, except for the source of devices. The heat and moisture balance equations for the public areas are: 


$$
\begin{gathered}
C \frac{d T_{a}}{d \tau}=Q_{i-o u t d o o r}+Q_{i-\text { tunnel }}+Q_{d}+Q_{p}+Q_{m v}+Q_{e} \\
V \frac{d c_{a}}{d \tau}=q_{i-\text { outdoor }}+q_{i-\text { tunnel }}+q_{p}+q_{m v}+q_{e}
\end{gathered}
$$

where $C$ is the heat capacity of air $\left(\mathrm{kJ} /{ }^{\circ} \mathrm{C}\right), T_{a}$ is the air temperature in station $\left({ }^{\circ} \mathrm{C}\right)$, $Q_{i-\text { outdoor }}$ is the heat gain from the unorganized air infiltration of outdoor $(\mathrm{kW})$, $Q_{i-\text { tunnel }}$ is the heat gain from the unorganized air infiltration of tunnel $(\mathrm{kW}), Q_{d}$ is the heat dissipation of the station devices $(\mathrm{kW}), Q_{p}$ is the heat dissipation of the personnel $(\mathrm{kW}), Q_{m v}$ is the heat added or removed by mechanical ventilation $(\mathrm{kW})$, and $Q_{e}$ is the heat gain from the envelope $(\mathrm{kW}) . V$ is the volume of the station $\left(\mathrm{m}^{3}\right), c_{a}$ is the humidity by volume of station air $\left(\mathrm{kg} / \mathrm{m}^{3}\right), q_{\text {i-outdoor }}$ is the moisture exchange with outdoor air $(\mathrm{kg} / \mathrm{h}), q_{i-t u n n e l}$ is the moisture exchange with tunnel air $(\mathrm{kg} / \mathrm{h}), q_{p}$ is the internal humidity generated by occupant activities $(\mathrm{kg} / \mathrm{h}), q_{m v}$ is the moisture added or removed by mechanical ventilation $(\mathrm{kg} / \mathrm{h})$, and $q_{e}$ is the desorption of hygroscopic moisture from the walls $(\mathrm{kg} / \mathrm{h})$.

This study focuses on the investigation of potential visual condensation on the interior surfaces of underground station envelopes, as well as the external surface of equipment. Specifically, the AGM and PSD systems (see Figure 4) are focused as they are the major electronic devices used in public areas to maintain the normal operation of the station. 

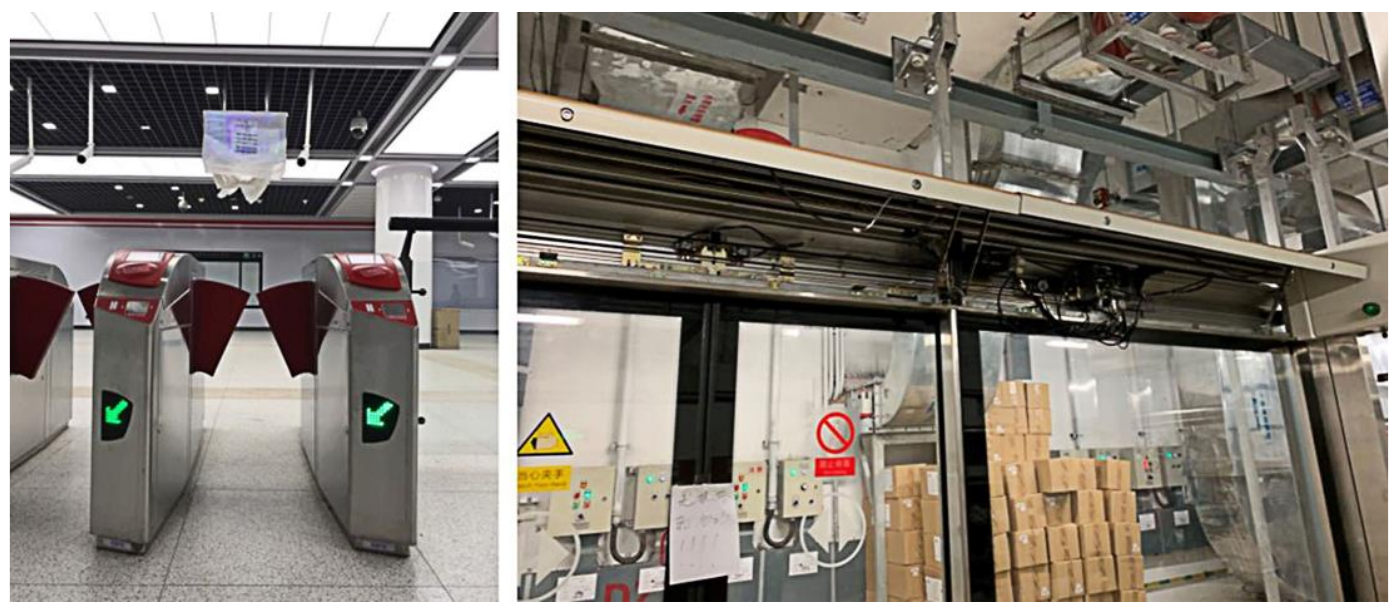

Figure 4. The automatic gate machine and the motor of the PSD system.

The characteristics of condensation are reflected by the temperature differences between the surface of objects and the indoor air dew point $\left(T_{\mathrm{d}}\right)$, with the moisture transfer in the envelope being ignored as the station was isolated from the concrete structure by a layer of silicate boards. The dew point temperature $T_{\mathrm{d}}$ is defined as 'the temperature at which condensation begins when the air is cooled at constant pressure ${ }^{28}$ and can be calculated from the equation ${ }^{29}$ below:

$$
T_{d}=\frac{243.04\left[\ln \left(\frac{R H}{100}\right)+\frac{17.625 T}{243.04+T}\right]}{17.625-\ln \left(\frac{R H}{100}\right)-\frac{17.625 T}{243.04+T}}
$$

where $T_{\mathrm{d}}$ is the dew point temperature $\left({ }^{\circ} \mathrm{C}\right)$ and $T$ is air temperature $\left({ }^{\circ} \mathrm{C}\right)$, and $R H$ stands for relative humidity in percent.

As soon as the surface temperature $\left(T_{\mathrm{s}}\right)$ is lower than $T_{\mathrm{d}}$, the water vapor in the air which meets the low-temperature surface condenses into water and releases heat. This criterion is used to determine whether the condensation will occur on the wall surface in this study for all the parameters needed are easy to measure. 


$$
T_{s} \leq T_{d}
$$

\subsection{On-site measurements}

The measurement objects are two underground stations on Tianjin Metro Line No. 5, one is short-term measured and the other is long-term measured. Based on the results of the two measurements are similar, the long-term measurement station is introduced here. The station investigated has been built since 2017 and now is in the commissioning phase. It is a 2-layers underground non-transfer station with PSDs, served by double tracks with an island platform. The indoor environment of the public areas was measured. The entrances and PSDs of the station were kept closing during the measurements and the trains did not stop at this station.

The on-site measurements were conducted from August $1^{\text {st }}$ to August $29^{\text {th }}$, during the hot and rainy period in Tianjin. The indoor air temperature and relative humidity $(\mathrm{RH})$ at the height of $1 \mathrm{~m}$ in the hall and $2.3 \mathrm{~m}$ in the platform, as well as outdoor climate were recorded. Figure 5 shows the locations of the measurement points and Figure 6 presents the onsite measurement situation in the station. The air temperature and $\mathrm{RH}$ were recorded by sensors every ten minutes at six measurement points. As the wall at B and D side is interior wall connected with the office room and has little heat transfer, the surface temperature of walls and the upper structure of PSDs was measured near the air test points by using the thermocouple which fixed on surfaces $\mathrm{A}$ and $\mathrm{C}$ at the hall and the upper structure of PSDs, respectively. The air temperature and RH in the tunnel were also tested in one day. 

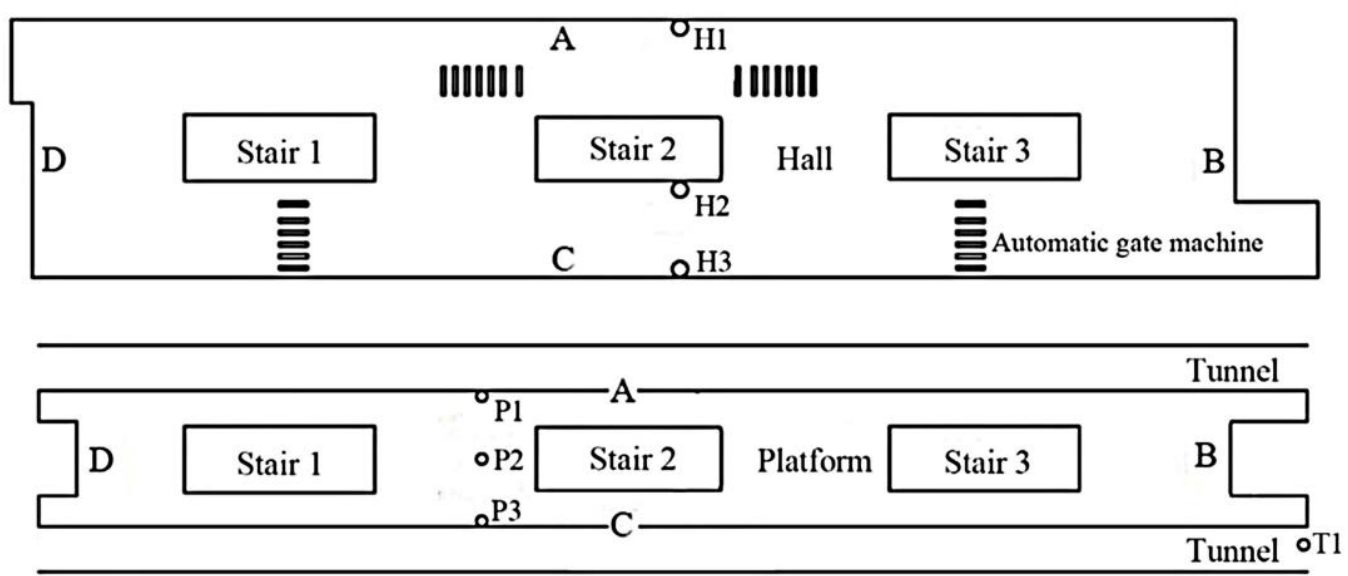

- Test points

Figure 5. Layout of the test points in the hall and platform.

For the experiment, all sensors, except the thermocouples, have been manufacturecalibrated. For thermocouples, the constant temperature water bath method has been used for the calibration. Detailed information is presented in Table 1.

\section{Table 1}

Measuring instrument information.

\begin{tabular}{|c|c|c|c|}
\hline Measuring instruments & Parameters & Range & Accuracy \\
\hline HOBO UX100 data & Temperature & $-20^{\circ} \mathrm{C}$ to $70{ }^{\circ} \mathrm{C}$ & $\pm 0.21^{\circ} \mathrm{C}$ \\
\hline logger & RH & $1 \%$ to $95 \%$ & $\pm 2.5 \%$ \\
\hline \multirow{2}{*}{ Testo $175 \mathrm{H} 1$} & Temperature & $-20^{\circ} \mathrm{C}$ to $55^{\circ} \mathrm{C}$ & $\pm 0.4^{\circ} \mathrm{C}$ \\
\hline & RH & $0 \%$ to $100 \%$ & $\pm 2 \%$ \\
\hline \multicolumn{4}{|l|}{ Platinum and Copper } \\
\hline \multicolumn{4}{|l|}{ Thermocouples } \\
\hline \multirow{3}{*}{ Testo $405 \mathrm{i}$} & Temperature & $-20^{\circ} \mathrm{C}$ to $60^{\circ} \mathrm{C}$ & $\pm 0.5^{\circ} \mathrm{C}$ \\
\hline & & & $\pm(0.1 \mathrm{~m} / \mathrm{s}+5 \%$ of \\
\hline & Velocity & $0 \mathrm{~m} / \mathrm{s}$ to $30 \mathrm{~m} / \mathrm{s}$ & $\mathrm{mv})(0 \mathrm{~m} / \mathrm{s}$ to $2 \mathrm{~m} / \mathrm{s})$ \\
\hline Fluke 568 infrared & & & \\
\hline thermometer & Temperature & $-40^{\circ} \mathrm{C}$ to $800^{\circ} \mathrm{C}$ & $\pm 1^{\circ} \mathrm{C}$ \\
\hline
\end{tabular}



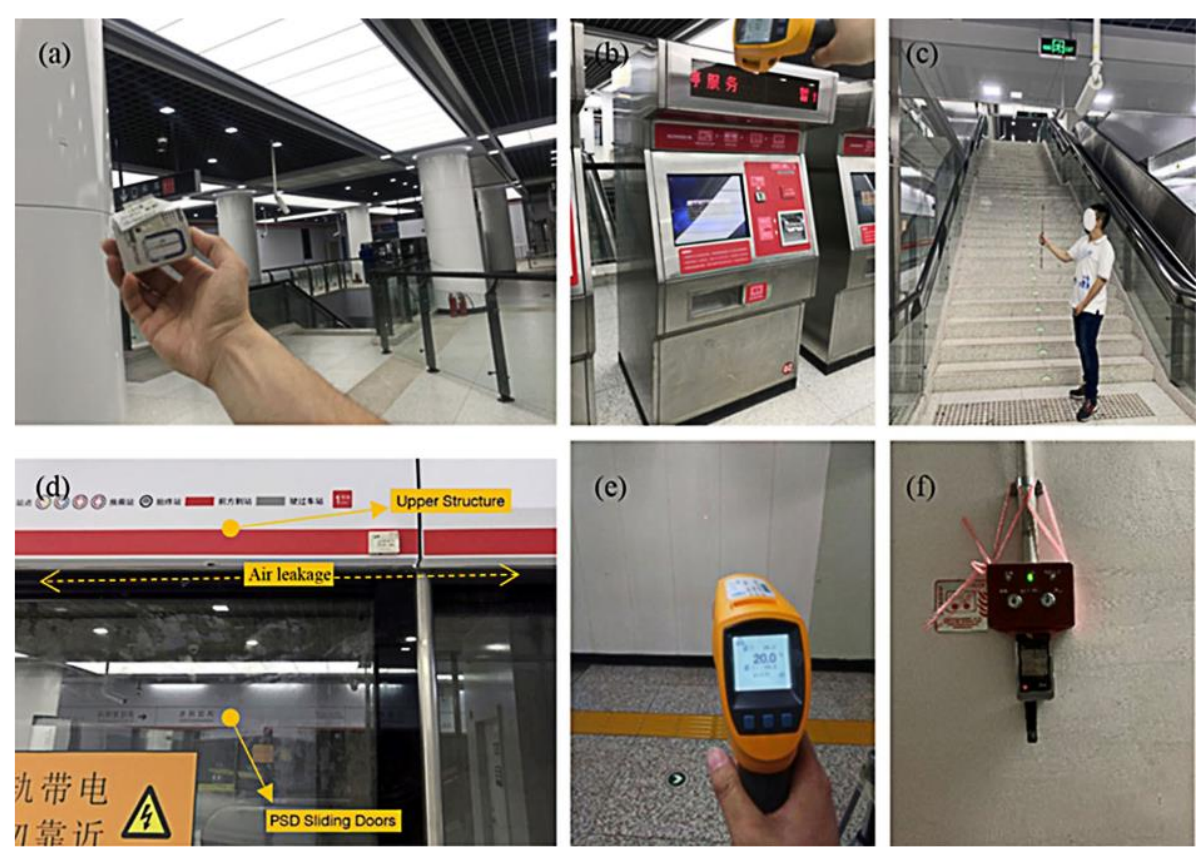

Figure 6. Onsite measurements in the station: (a) and (d) installing the sensor; (b) and (e) measuring device and wall surface temperature; (c) measuring velocity at openings; and (f) test point $\mathrm{T} 1$ settled in the tunnel.

\subsection{Numerical approach}

\subsubsection{Model setup}

In order to assess the overall moisture risk in the station, a numerical approach based on the computational fluid dynamics simulation was conducted to predict the temperature and $\mathrm{RH}$ field. Since the turbulence and temperature and $\mathrm{RH}$ field in the underground station were complex, assumptions were made for quantitative analysis according to the existing studies ${ }^{17,30}$ :

(1) The air in the underground station is considered as incompressible fluid;

(2) The air meets the Boussinesq approximation;

(3) All radiation heat transfer is ignored;

(4) The temperature and RH of air from accesses and the leakage are considered constant 
values because of the small changes;

(5) The flow field was assumed to be steady-state;

(6) There are always four staff assumed on duty in the station.

In addition, because the doors of the entrance and the PSDs were kept closing, as well as the existing of the piston wind shafts, the value of air velocity at the staircase caused by the piston effect was ranged from $0 \mathrm{~m} / \mathrm{s}$ to $0.3 \mathrm{~m} / \mathrm{s}$ within the few seconds of the train passing by. Thus, the movement of trains in the tunnel was omitted in this simulation.

The geometric model of the station is illustrated in Figure 7. The size of hall is $92.5 \mathrm{~m}$ (L) $\times 18.6 \mathrm{~m}(\mathrm{~W}) \times 5.0 \mathrm{~m}(\mathrm{H})$, and the size of the platform is $112.0 \mathrm{~m}(\mathrm{~L}) \times 12.0 \mathrm{~m}(\mathrm{~W}) \times 4.5$ $m(H)$. Additionally, the size of the stairs' openings between the station hall and platform are $13.7 \mathrm{~m}(\mathrm{~L}) \times 4.8 \mathrm{~m}(\mathrm{~W}), 13.3 \mathrm{~m}(\mathrm{~L}) \times 4.6 \mathrm{~m}(\mathrm{~W}), 13.7 \mathrm{~m}(\mathrm{~L}) \times 4.8 \mathrm{~m}(\mathrm{~W})$, respectively. The air supply and exhaust ducts are available on both sides of the station hall, with a gap of $2 \mathrm{~m}$ between them. On the platform, the air supply and exhaust ducts were positioned separately on each side, with a gap of $8 \mathrm{~m}$. Furthermore, the dimensions and boundary conditions of other objects in the station are shown in Table 2.

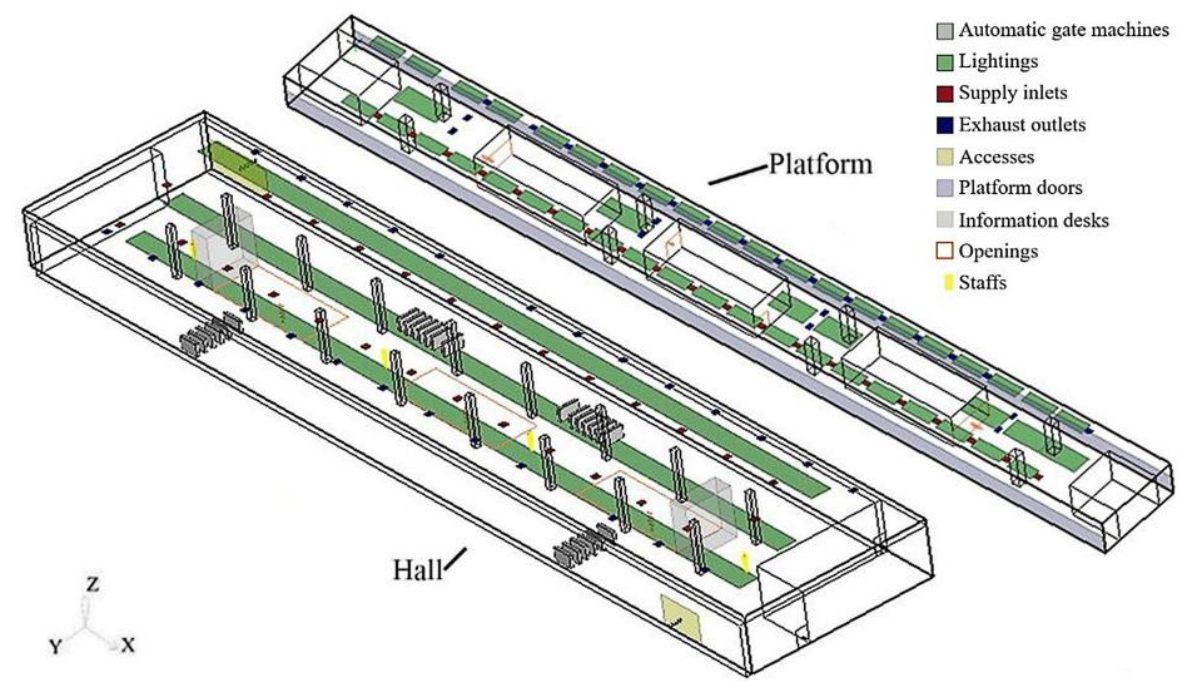


Figure 7. Schematic diagram of the station.

\section{Table 2}

Dimensions and boundary conditions for the objects in the station.

\begin{tabular}{lll}
\hline Item & Dimensions $(\mathrm{m})$ & Boundary conditions \\
\hline Automatic gate machines & $2.5 \times 0.6 \times 1.2$ & $25 \mathrm{~W}$ \\
Lightings & $80 \times 1.6 ; 3.8 \times 1.6$ & $13 \mathrm{~W} / \mathrm{m}^{2}$ \\
Supply inlets & $0.6 \times 0.6$ & Velocity inlet $(2 \mathrm{~m} / \mathrm{s})$ \\
Exhaust outlets & $0.8 \times 0.6$ & Velocity inlet $(3 \mathrm{~m} / \mathrm{s})$ \\
Accesses & $4.8 \times 3 ; 6.5 \times 3$ & Pressure outlet \\
Platform doors & $2.2 \times 111.6$ & $9 \mathrm{~W} / \mathrm{m}^{2}$ \\
Information desks & $8 \times 2.1 \times 5$ & Adiabatic wall \\
Openings & $13.7 \times 4.8 ; 13.3 \times 4.6 ; 13.7 \times 4.8$ & \\
Staff & $5.9 \times 2.5 ; 2.2 \times 2.5 ; 2.2 \times 2.5 ; 5.9 \times 2.5$ & Velocity inlet $\left(24{ }^{\circ} \mathrm{C} ; 75 \%\right)$ \\
Walls & $0.3 \times 0.8 \times 1.7$ & $31{ }^{\circ} \mathrm{C} ; 96 \mathrm{~g} / \mathrm{h}(0.0267 \mathrm{~g} / \mathrm{s})$ \\
Upper structure of PSDs & $112 \times 0.5$ & $23{ }^{\circ} \mathrm{C} ; 1.5 \mathrm{~g} /\left(\mathrm{m}^{2} \cdot \mathrm{h}\right)(0.0004$ \\
Air leakage of PSDs & $112 \times 0.05$ & $\left.\mathrm{~g} /\left(\mathrm{m}^{2} \cdot \mathrm{s}\right)\right)$ \\
\hline
\end{tabular}

Notes: the velocity value for different scale of opening under the design condition was $0.8 \mathrm{~m} / \mathrm{s}$ for $5.9 \times 2.5 ; 1.2 \mathrm{~m} / \mathrm{s}$ for $2.2 \times 2.5 ; 0.18$ for $13.7 \times 4.8$ and $0.21 \mathrm{~m} / \mathrm{s}$ for $13.3 \times 4.6$. The velocity value for different scale of opening when increasing the exhaust air volume was $1 \mathrm{~m} / \mathrm{s}$ for $5.9 \times 2.5 ; 1.5$ $\mathrm{m} / \mathrm{s}$ for $2.2 \times 2.5 ; 0.22$ for $13.7 \times 4.8$ and $0.27 \mathrm{~m} / \mathrm{s}$ for $13.3 \times 4.6$.

The boundary conditions for this station model include flow obstacles of solid objects; heat and moisture transfer from different objects; supply airflow; and airflows from the outdoor through accesses and the tunnel through the leakage of PSDs. According to the design manual provided by the Tianjin Metro company, the total power of AGMs was 25 $\mathrm{W}$ and the heat release rate from lighting was fixed as $13 \mathrm{~W} / \mathrm{m}^{2}$. The supply inlet and 
exhaust outlet were settled as the velocity inlet, and the velocity value was $2 \mathrm{~m} / \mathrm{s}$ and 3 $\mathrm{m} / \mathrm{s}$ based on the design condition, respectively. The supplied air parameters for model validation were $\mathrm{T}=28^{\circ} \mathrm{C}, \mathrm{RH}=66.2 \%$, and the parameters of the exhaust air were default to the ambient environment. For the PSD system, the comprehensive heat transfer coefficient of the sliding door is $3 \mathrm{~W} /\left(\mathrm{m}^{2} \cdot{ }^{\circ} \mathrm{C}\right),{ }^{31}$ and the temperature difference between platform air and tunnel air is ranged from $2-4{ }^{\circ} \mathrm{C}$, hereby, a temperature difference of $3{ }^{\circ} \mathrm{C}$ was used and the heat flux was obtained as $9 \mathrm{~W} / \mathrm{m}^{2}$. The surface of the upper structure of PSDs was $23{ }^{\circ} \mathrm{C}$. The information desks, partition walls, stairs, and pillars were settled as adiabatic walls. The openings were settled as the velocity inlet as the hall and platform were simulated separately. The velocity of the openings at the platform level was obtained by measurements, and the velocity of the openings at the hall level were calculated according to the flow conservation. The staff and side walls of the hall were considered as constant wall temperature boundary conditions and the surface temperature were $31^{\circ} \mathrm{C}$ and $24^{\circ} \mathrm{C}$, respectively. Staff in the station were also the source of moisture and the moisture gain was $96 \mathrm{~g} / \mathrm{h} .{ }^{32}$ Other sources of moisture include walls $\left(1.5 \mathrm{~g} /\left(\mathrm{m}^{2} \cdot \mathrm{h}\right)\right.$ according to the design manual) and humid tunnel air that penetrates into the station through the leakage of PSDs.

The boundary conditions of accesses and leakage of PSDs were settled as the pressure outlet, and the parameters were obtained by measurements. Figure 8 shows the temperature and $\mathrm{RH}$ measured at the access and tunnel, and the frequent fluctuations of the parameters were caused by train passing and the overall trend was stable. It can be seen in Figure 8 that the temperature fluctuates around $25{ }^{\circ} \mathrm{C}$ within $1{ }^{\circ} \mathrm{C}$, and $\mathrm{RH}$ 
fluctuates around $70 \%$ within $5 \%$ in the access; the temperature fluctuates around $23{ }^{\circ} \mathrm{C}$ within $0.5{ }^{\circ} \mathrm{C}$, and $\mathrm{RH}$ fluctuates around $80 \%$ within $5 \%$ in the tunnel. Considering the fluctuations of these parameters are small as depicted in Figure 9, the air through accesses were set $\mathrm{T}=25^{\circ} \mathrm{C}, \mathrm{RH}=70 \%$; that of the air through the leakage were $\mathrm{T}=23{ }^{\circ} \mathrm{C}, \mathrm{RH}=$ $80 \%$, respectively.
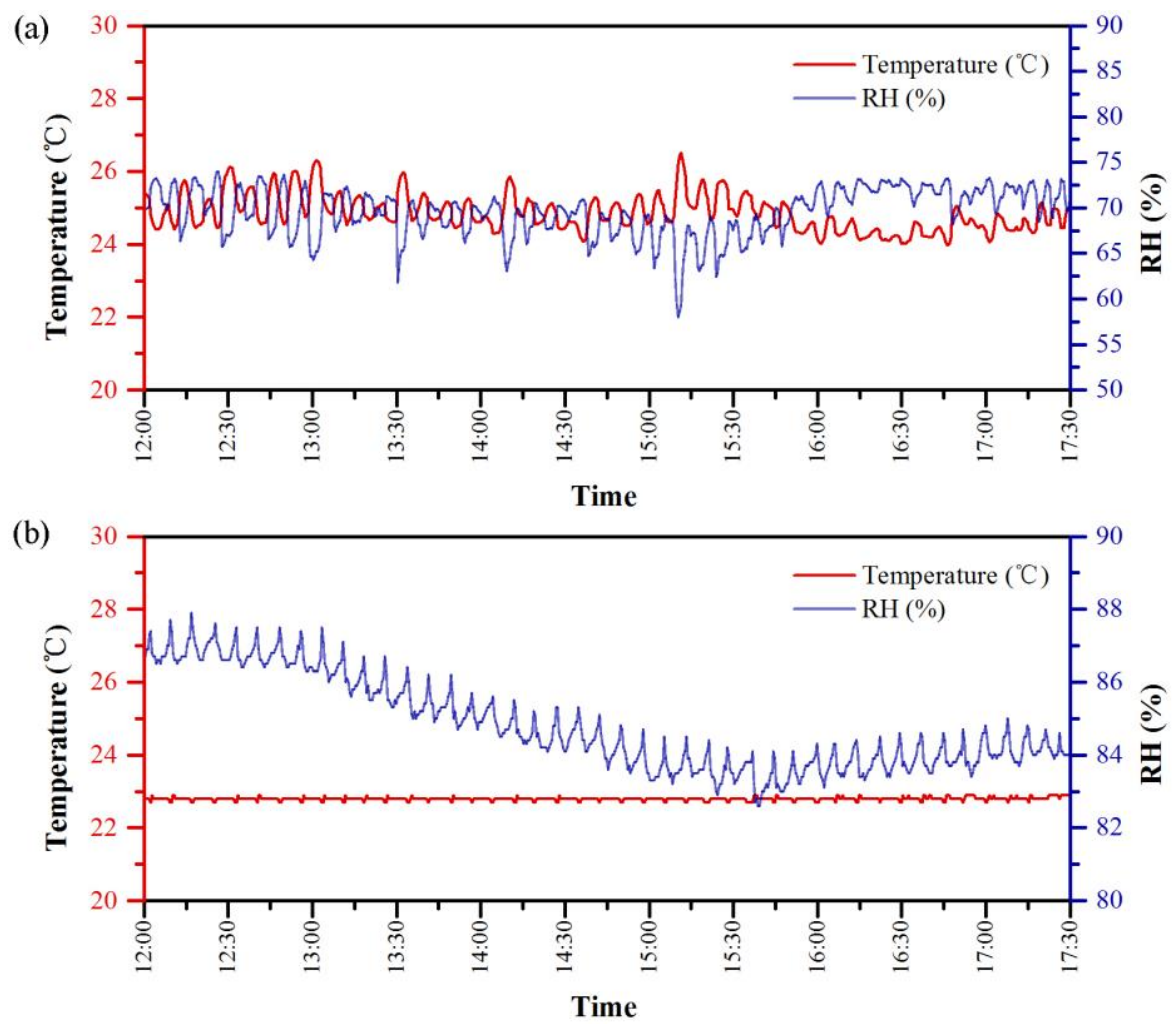

Figure 8. (a) one of the access air temperature and $\mathrm{RH}$ profile and (b) tunnel air temperature and $\mathrm{RH}$ profile with the interval of $30 \mathrm{~s}$ in summer.

(a)

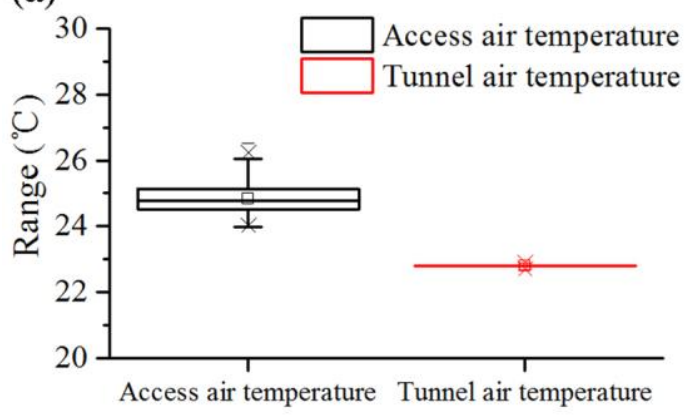

(b)

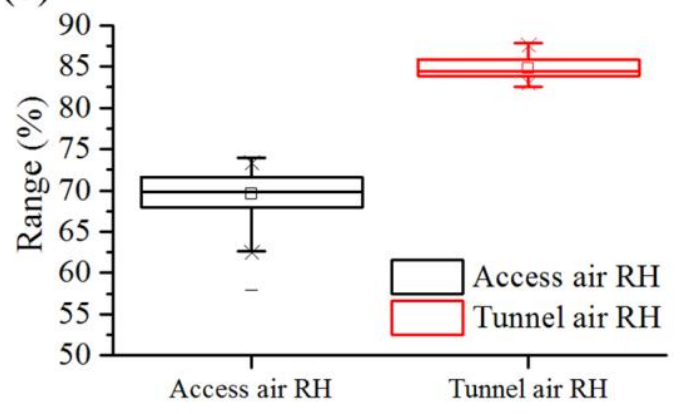


Figure 9. Boxplot of the (a) temperature and (b) RH at test points

The commercial software Airpak was applied to solve the governing equations with the finite volume method. As the computational accuracy can be improved significantly by adopting a reasonable numerical model, the standard $\mathrm{k}-\varepsilon$ turbulence model has been used due to its well-known accuracy for the indoor airflow design. ${ }^{33}$ The governing equations for the standard $k-\varepsilon$ model are as follows:

$$
\frac{\partial}{\partial x_{i}}\left(\rho U_{i} \varnothing\right)=\frac{\partial}{\partial x_{i}}\left(\Gamma_{\varnothing} \frac{\partial \emptyset}{\partial x_{i}}\right)+S_{\varnothing}
$$

where $\varnothing$ is a transport variable such as continuity $(\varnothing=1)$, enthalpy, concentration of moisture or velocity; $\rho$ is density $\left(\mathrm{kg} / \mathrm{m}^{3}\right), \Gamma_{\varnothing}$ is a diffusion coefficient, $U_{i}$ is a mean velocity component $(\mathrm{U}, \mathrm{V}, \mathrm{W})$, and $S_{\varnothing}$ is a mean source term. The $\varnothing, \Gamma_{\varnothing}$ and $S_{\varnothing}$ are further listed in the Table $3 .{ }^{34}$

\section{Table 3}

Dimensions and boundary conditions for the objects in the station.

\begin{tabular}{cccc}
\hline Equation Type & $\emptyset$ & $\Gamma_{\varnothing}$ & $S_{\varnothing}$ \\
\hline Continuity & 1 & 0 & 0 \\
X-momentum & $u_{1}$ & $\mu+\mu_{t}$ & $-\frac{\partial p}{\partial x}$ \\
Y-momentum & $u_{2}$ & $\mu+\mu_{t}$ & $-\frac{\partial p}{\partial y}$ \\
Z-momentum & $u_{3}$ & $\mu+\mu_{t}$ & $-\frac{\partial p}{\partial z}-g$ \\
Energy & $T$ & $\frac{\mu}{p_{r}}+\frac{\mu_{t}}{\sigma_{T}}$ & $S_{T}$ \\
Turbulent kinetic energy & $k$ & $\mu+\frac{\mu_{t}}{\sigma_{k}}$ & $G_{k}-\rho \varepsilon$ \\
Dissipation rate of k & $\varepsilon$ & $\mu+\frac{\mu_{t}}{\sigma_{\varepsilon}}$ & $\frac{\varepsilon}{k}\left(C_{1 \varepsilon} G_{k}-C_{2 \varepsilon} \rho \varepsilon\right)$ \\
\hline
\end{tabular}


Where $\mu$ is molecular viscosity; $\mu_{t}$ is eddy viscosity; $G_{k}=\mu_{t}\left(\frac{\partial u_{i}}{\partial x_{j}}+\frac{\partial u_{j}}{\partial x_{i}}\right) \frac{\partial u_{i}}{\partial x_{j}} ; C_{1 \varepsilon}=1.44$; $C_{2 \varepsilon}=1.92 ; \sigma_{k}=1 ; \sigma_{\varepsilon}=1.3$

Moreover, the continuity, momentum and energy conservation equations were solved by employing the finite volume, the second-order upwind scheme and the SIMPLE algorithm. The convergence residual magnitudes for continuity and momentum were set to $10^{-4}$, while the residual of energy is $10^{-6}$.

\subsubsection{Model validation}

A grid-dependent study was performed by three different grid resolutions for both station hall and platform, respectively. The study used nonuniform distribution on the grid nodes concentrated near the supply inlets and walls. The maximum size of the grids are $0.4 \mathrm{~m}$, $0.4 \mathrm{~m}$ and $0.2 \mathrm{~m}$ in $\mathrm{X}, \mathrm{Y}$ and $\mathrm{Z}$ axis, respectively. Figure 10 shows the results from the grid dependence study for the hall and the platform. From Figure 10a, it could be found that the dimensionless air temperature and humidity ratio $(w)$ profiles near the wall and the stair were approximately coincident, and the curve of Grid-H2 seemed to be closer to the measured results. Figure $10 \mathrm{~b}$ depicts the grid convergence study for platform and the curve of Grid-P2 is between the other two curves and closer to the measured results. Generally, the difference between the two finer grids is very small for both hall and platform models. Therefore, Grid-H2 and Grid-P2 were considered sufficient. Given necessary assumptions of the constructed models and the system errors of instruments, it is concluded that the simulated results exhibit reasonably good agreement with the tested results and the models can be adopted to predict the $\mathrm{RH}$ field in the following analysis. 
(a)

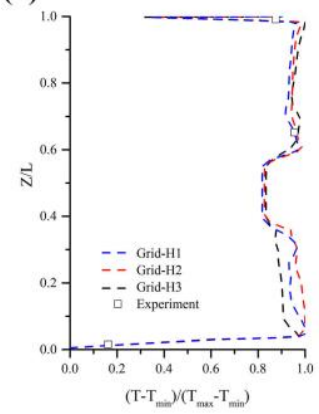

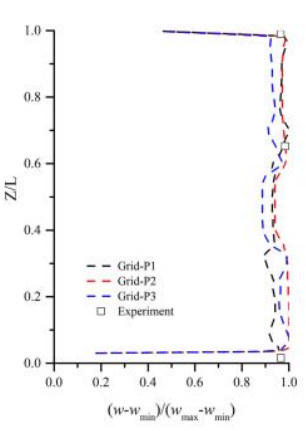

(b)

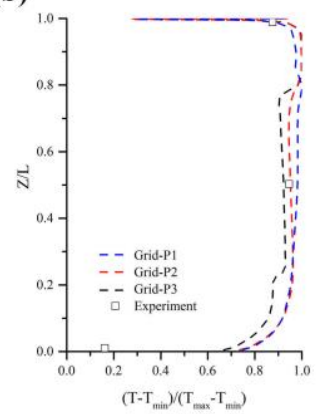

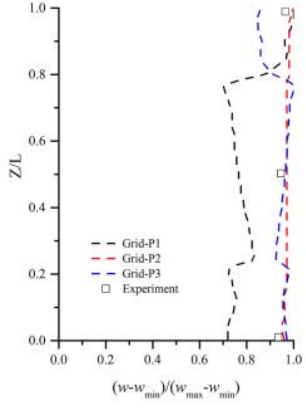

Figure 10. Grid dependence study: (a) grids for the hall (H1-1805481 nodes, H2-2808759 nodes, and H3-3011977 nodes) and (b) grids for the platform (P1-1085589 nodes, P21831356 nodes, and P3-2089446 nodes).

\subsubsection{Modelling of different scenarios}

To analysis the moisture condensation in a common scenario, the designed ventilation condition (scenario 1) was used in this study. The supplied air parameters for public areas under the designed condition are $\mathrm{T}=26.4{ }^{\circ} \mathrm{C}$ and $\mathrm{RH}=63 \%$. In addition, to reduce the risk of condensation under design conditions, two dehumidification solutions have been proposed. The principle of selecting a dehumidification solution was that it should be universal, matured, easy-to-operate and with appropriate cost. Solution 1 was to reduce the RH by increasing the exhaust air volume (scenario 2); Solution 2 was to reduce the RH by using industrial dehumidifiers (scenario 3 ).

\section{Results and discussion}

\subsection{Measurement results}

As shown in Figure 11, the air temperatures in both sides of the station hall and the platform changed within the range of $23.9{ }^{\circ} \mathrm{C}$ to $28.5{ }^{\circ} \mathrm{C}$ and $22.9{ }^{\circ} \mathrm{C}$ to $28.4{ }^{\circ} \mathrm{C}$, respectively. The RH changed within the range of $32.4 \%$ to $87.9 \%$ and $37.8 \%$ to $94.1 \%$, 
respectively. The air temperature was relatively stable, with a fluctuation range of around $5{ }^{\circ} \mathrm{C}$. The $\mathrm{RH}$, however, was varying significantly, with a maximum fluctuation of nearly $60 \%$. Because it was a period of concentrated rainfall days in early August, and the maximum RH of outdoor can be reached $92 \%$. In most periods, the temperature in the hall was higher than that of the platform, and the RH in the hall was lower than that of the platform.
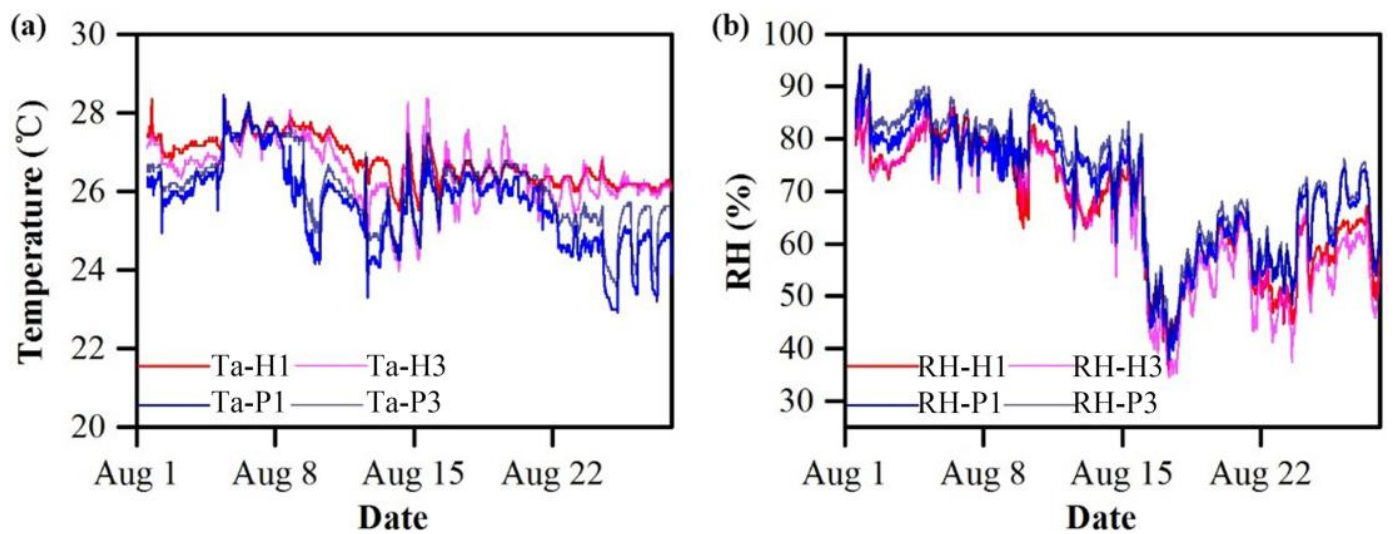

Figure 11. Station air temperature and RH at test points.

The frequency distribution of the $\mathrm{RH}$ for the public areas represented by test points $\mathrm{H} 2$ and P2 over test period is presented in Figure 12. In this study, the humidity environment is classified into four levels: "not wet" $(\mathrm{RH} \leqslant 70 \%)$, "slightly wet" $(70 \%<\mathrm{RH} \leqslant$ $80 \%)$, "wet" $(80 \%<\mathrm{RH} \leqslant 90 \%)$ and "very wet" $(\mathrm{RH}>90 \%) .{ }^{5}$ 


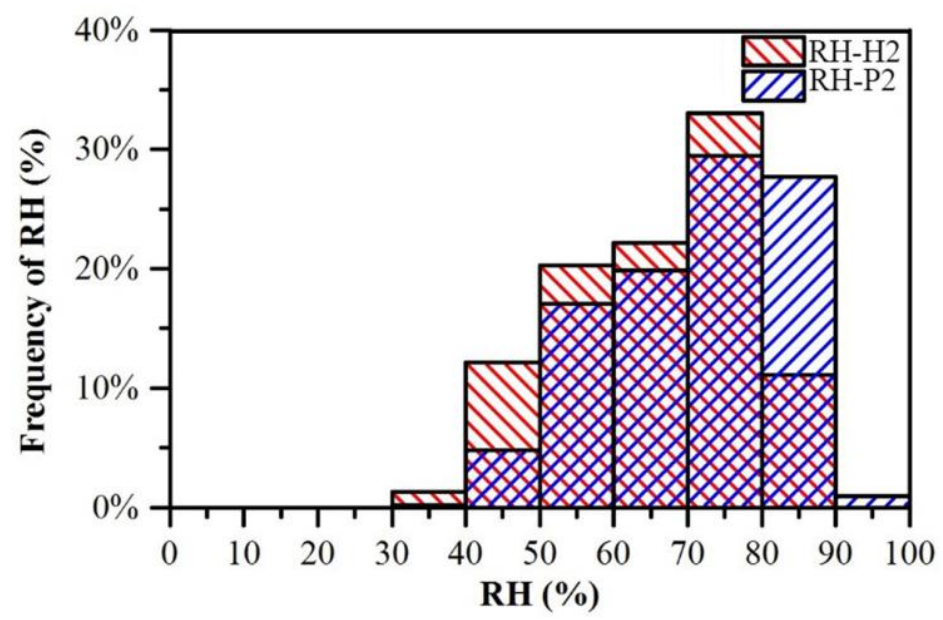

Figure 12. Frequency of the station's RH over the test period.

In Figure 12, it can be observed that the proportion of the "not wet" level in the hall was $55.9 \%$; the proportion of "slightly wet" level was $33 \%$ and the "wet" level was $11.1 \%$, "very wet" were not observed over the test period. Conversely, for almost $30 \%$ of the testing time, the platform had RH levels of 'wet' or even 'very wet', which indicated that the interior surface of the platform has a relative high risk of condensation than the hall.

Figure 13 demonstrates that the surface temperature of the interior walls on both $\mathrm{A}$ and $\mathrm{C}$ sides in the station hall was kept around $24{ }^{\circ} \mathrm{C}$, which was always higher than the dew point temperature of the surrounding air. Figure 14 shows that the upper structure surface temperature of the PSDs on both A and C sides were changing within the range of $20.1^{\circ} \mathrm{C}$ to $25.3{ }^{\circ} \mathrm{C}$. There was a period when the surface temperature was lower than the dew point temperature of the surrounding air, which means the occurrence of condensation on the surface and further confirms that the platform was facing a greater risk of condensation than the hall. Moreover, by observing the data, the condensation usually occurs in the early morning and rainy days. 

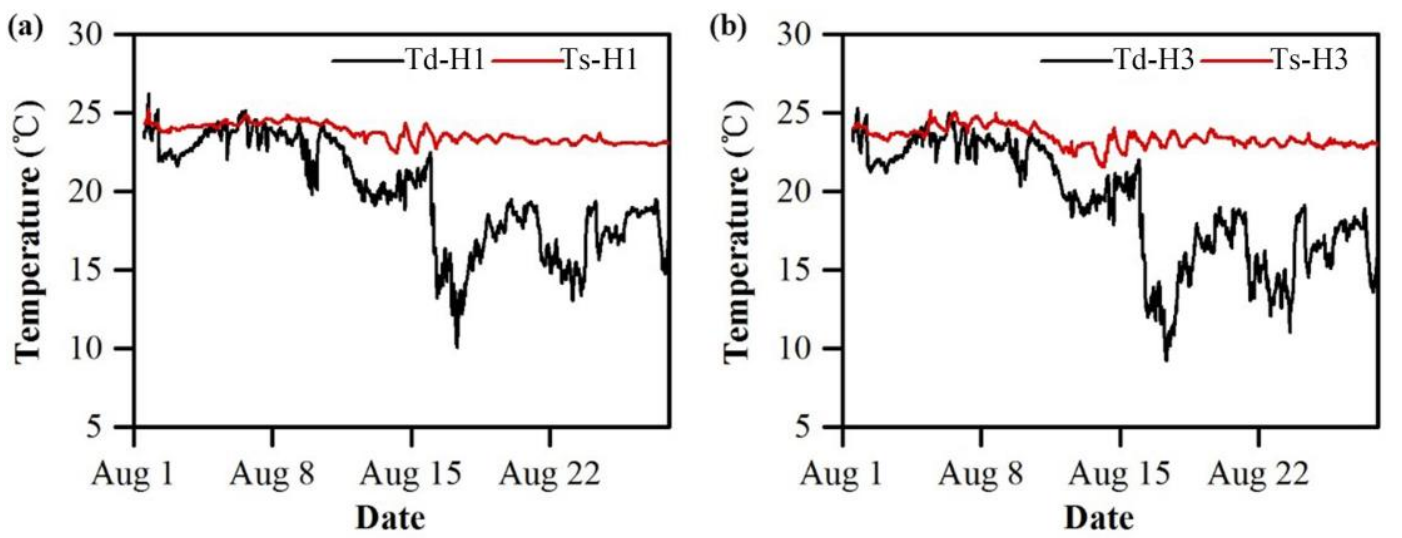

Figure 13. Comparison of the interior wall surface temperature and the hall air dew point temperature.
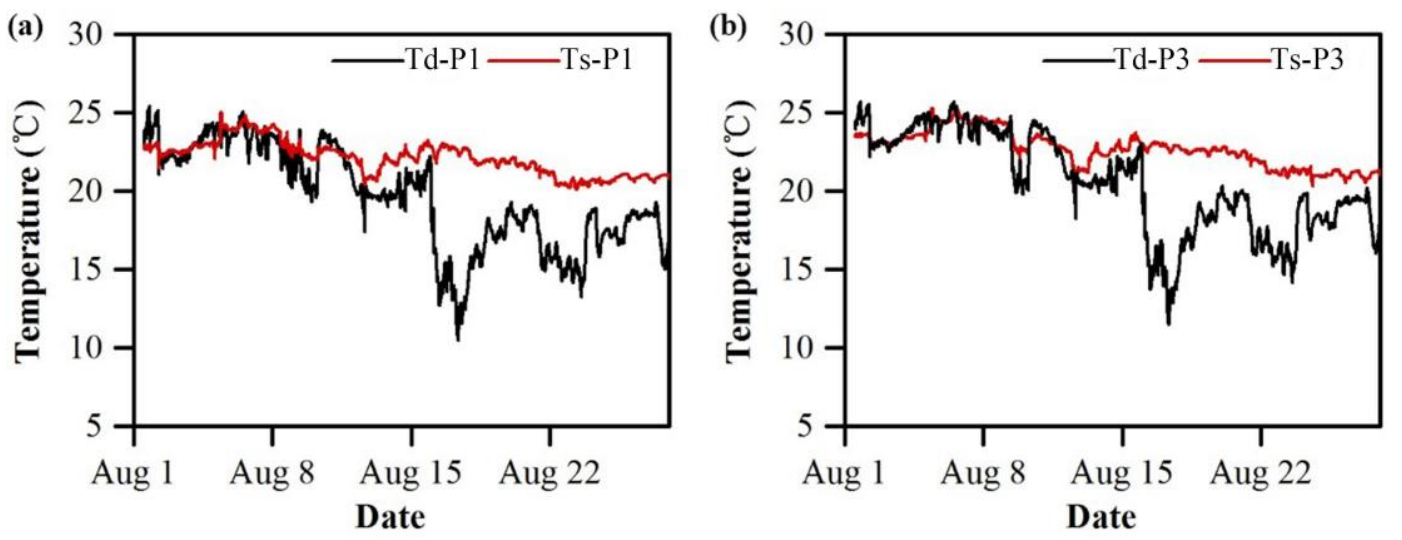

Figure 14. Comparison of the upper structure surface temperature and the platform air dew point temperature.

\subsection{Simulation results}

As the wall surface temperature was field measured and its moisture risk was analysed, the moisture risk of AGMs and motors of the PSD system was explored by simulation in different scenarios. Moreover, the height of $1 \mathrm{~m}$ in the hall and $2.5 \mathrm{~m}$ in the platform were monitored in the simulation as the AGMs and motors were distributed at these height levels. If the RH level at these heights is too high, the normal operation of these equipment would be threatened. Based on the premise of keeping electronic devices safety and occupant health requirements, the standard for controlling indoor moisture level is that 
the $\mathrm{RH}$ value ought to be $<70 \% .{ }^{35}$ In other words, the indoor moisture should keep in "not wet" level.

\subsubsection{RH field of the hall in different scenarios}

Figure 15a presents the distribution of $\mathrm{RH}$ in scenario 1 and it can be seen that the RH was between $65 \%$ and $70 \%$ in most areas, with the maximum value of RH exceeding $70 \%$ near the wall surfaces of both sides. The value of $\mathrm{RH}$ of the air around AGMs on the A side was about $67 \%$, and around AGMs on the C side was higher, between $65 \%$ to $72 \%$.

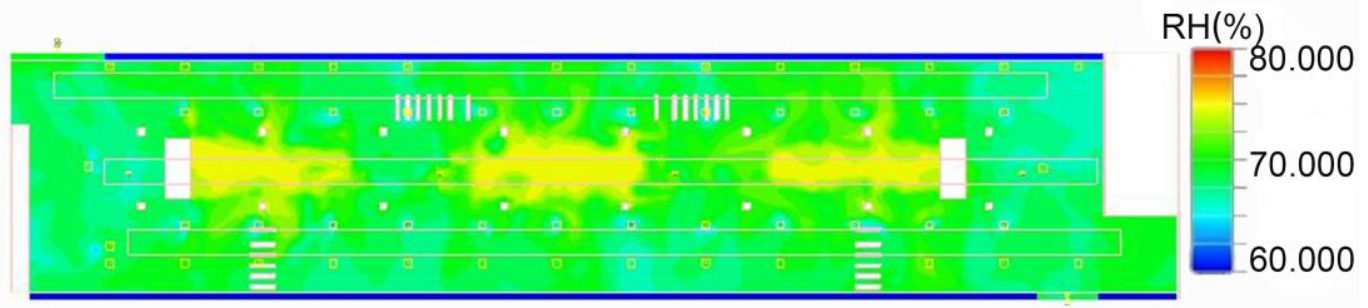

(a) The designed ventilation condition (scenario 1)

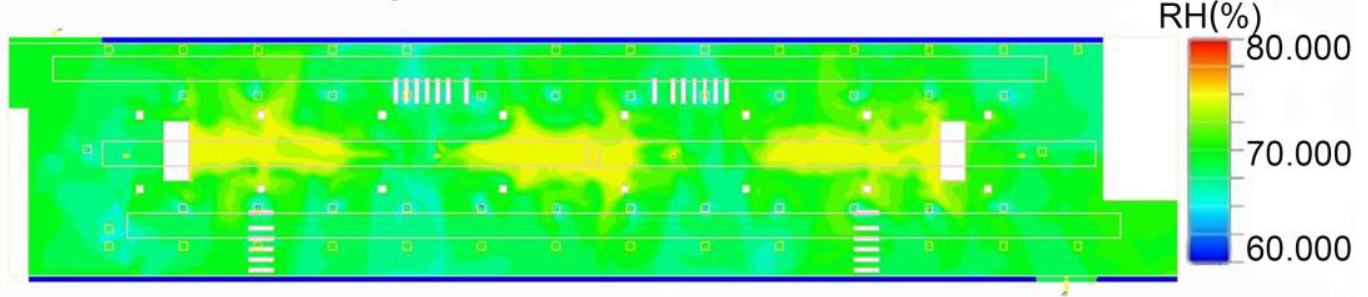

(b) Solution 1 (scenario 2)

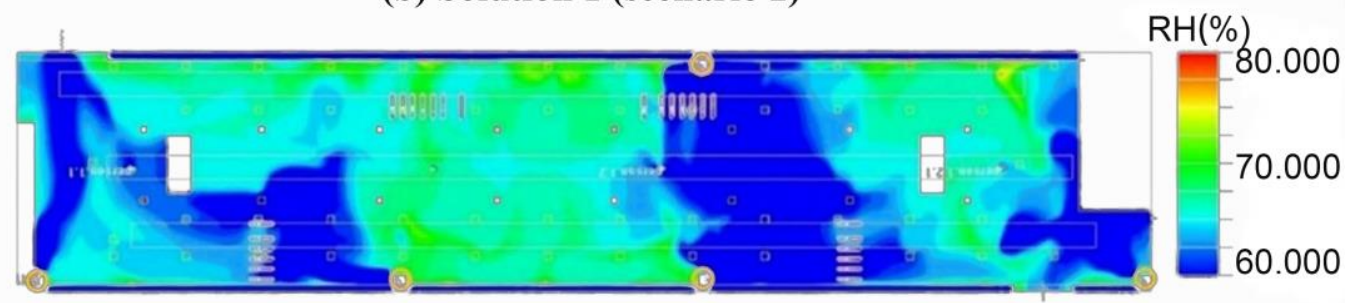

(c) Solution 2 (scenario 3)

Figure 15. The RH distribution in the plane $\mathrm{Z}=1 \mathrm{~m}$ of the hall: (a) the designed ventilation condition (scenario 1), (b) solution 1 (scenario 2) and (c) solution 2 (scenario 3).

To reduce indoor RH level, the exhaust air speed was increased to $4.5 \mathrm{~m} / \mathrm{s}$ to exclude the humid air in the public area in scenario 2 . Figure $15 \mathrm{~b}$ shows that the RH level around the AGMs on the A side was ranging between $64 \%$ and $69 \%$, and ranging between $64 \%$ and 
$70 \%$ on the $\mathrm{C}$ side, basically meeting the criterion.

In scenario 3, the industrial dehumidifier was used to improve the moisture environment in the design condition. The industrial dehumidifiers manage the air through its evaporator and condensers. When the evaporator coil picks up heat from the incoming air, the condenser coil releases heat into the outlet air and then mixes with the air downstream of the outlet. ${ }^{36}$ As the placement of industrial dehumidifiers can be different, the results presented here were the best results obtained by several attempts of changing the positions and directions.

For the hall level, five industrial dehumidifiers were arranged as shown in Figure 15c. It can be seen that the horizontal RH distribution in the hall was clearly divisional due to the use of industrial dehumidifiers. The level of RH around AGMs was basically around $60 \%$, which fully met the dehumidification target. The area with relative high level of RH appeared in the middle area, which was away from AGMs, and the highest value of RH was less than $72 \%$. Areas at both ends of the hall also had a good dehumidification effect, with both values were below $70 \%$.

\subsubsection{RH field of the platform in different scenarios}

Figure 16a exhibits the distribution of $\mathrm{RH}$ in the platform in scenario 1 . It can be seen that the $\mathrm{RH}$ was ranging from $68 \%$ to $75 \%$ at the $\mathrm{A}$ (supply air) side and $75 \%$ to $85 \%$ at the $\mathrm{C}$ (exhaust air) side. The maximum value of $\mathrm{RH}$ reached $85 \%$ at the exhaust side, which is not good for the operation of motors.

According to Figure 16b, the level of RH of most areas of supply air side was between 
$70 \%$ and $75 \%$, and the $\mathrm{RH}$ of the exhaust air side remained between $80 \%$ and $85 \%$. In scenario 2 , increasing the exhaust air speed seems to inhale more humid air from the tunnel through the leakage of PSDs, resulting in a higher air RH distribution than that of scenario 1.

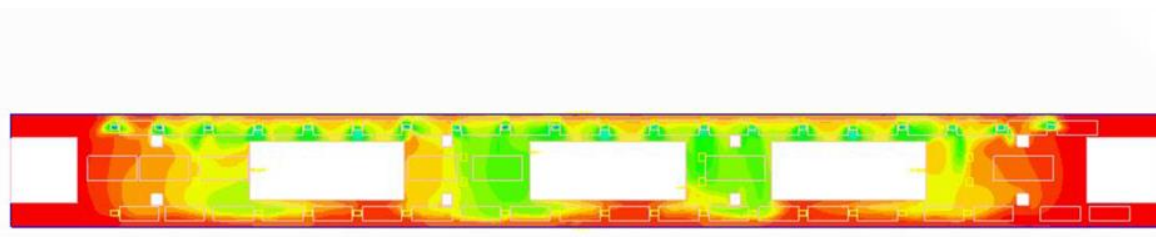

$\mathrm{RH}(\%)$ 85.000

(a) The designed ventilation condition (scenario 1)

72.500

60.000

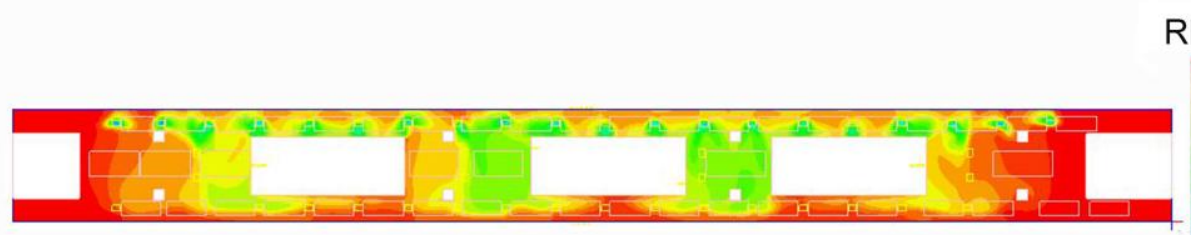

$\mathrm{RH}(\%)$

85.000

(b) Solution 1 (scenario 2)

72.500

60.000

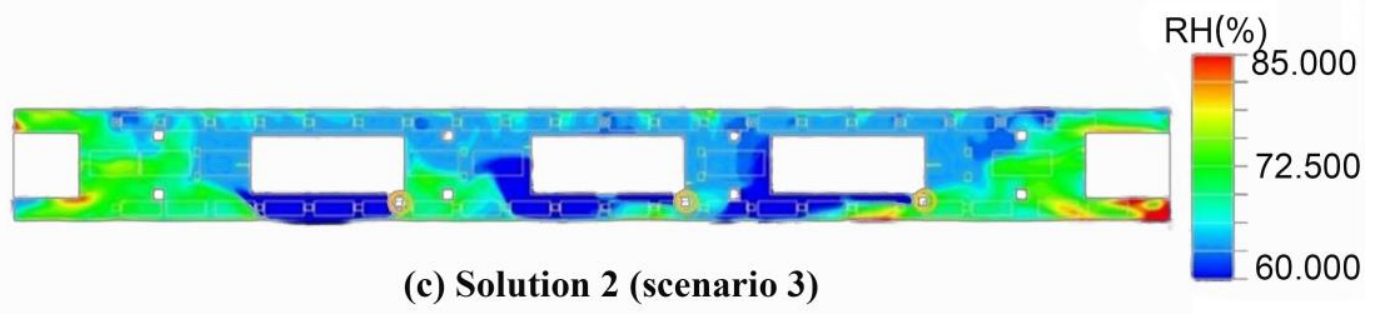

Figure 16. The RH distribution in the plane $\mathrm{Z}=2.5 \mathrm{~m}$ of the platform: (a) the designed ventilation condition (scenario 1), (b) solution 1 (scenario 2) and (c) solution 2 (scenario $3)$.

In scenario 3, three industrial dehumidifiers were arranged at the exhaust inlets' side on the platform, as shown in Figure 16c. It can be observed that after using them, the air RH of most areas on this side was between $60 \%$ and $71 \%$. In addition, although the levels of $\mathrm{RH}$ at both ends of the platform were relatively high, these areas were small, which would not bring hazards to the normal operation of PSDs. Therefore, solution 2 achieved the dehumidification target at this level. 


\subsubsection{Quantitative comparison of different scenarios}

To compare the levels of moisture around the equipment in different scenarios more intuitively, the values of $\mathrm{RH}$ and humidity ratio $(w)$ at the height of $1 \mathrm{~m}$ of the hall and 1 $\mathrm{cm}$ away from the AGMs, as well as at the height of $2.5 \mathrm{~m}$ of the platform and $1 \mathrm{~cm}$ away from the PSDs, were used, respectively. The minimum, maximum, and average values of RH and $w$ at these locations were counted separately at both A and C sides of the station.

The comparison of the RH and $w$ in different scenarios has been presented in Table 4 and Table 5. Comparing with scenario 1, the ranges of RH in scenario 2 around the AGMs at both sides of the hall were similar, but the average value of RH dropped in most locations. In the platform, the differences of both sides can be attributed to the layout of the ventilation ducts, as the supply air duct is away from the exhaust air duct, and so the exhaust air has little effect on the humidity of surrounding air. When comparing scenario 3 and scenario 1 , the average value of $\mathrm{RH}$ decreased in all locations, and the rate was higher than scenario 2. This indicated that the dehumidification effect of industrial dehumidifiers was more significant than that of increasing exhaust air volume.

\section{Table 4}

Comparison of $\mathrm{RH}$ in different scenarios.

\begin{tabular}{c|cccccccc}
\hline Location & \multicolumn{3}{c}{ Air near the AGMs } & \multicolumn{2}{c}{ Air near the upper structure of PSDs } \\
& \multicolumn{2}{c}{ Side A } & \multicolumn{2}{c}{ Side C } & \multicolumn{2}{c}{ Side A } & \multicolumn{2}{c}{ Side C } \\
Scenarios & range & average & range & average & range & average & range & average \\
\hline Scenario 1 & $65.8-71 \%$ & $69.9 \%$ & $66.3-72 \%$ & $70.8 \%$ & $79.5-85 \%$ & $81.3 \%$ & $83.1-85 \%$ & $83.4 \%$ \\
Scenario 2 & $64-70 \%$ & $68.3 \%$ & $64.7-71 \%$ & $70.1 \%$ & $82.9-85 \%$ & $82.6 \%$ & $83.2-85 \%$ & $84.2 \%$ \\
Scenario 3 & $60-70 \%$ & $63.5 \%$ & $60-67 \%$ & $61.4 \%$ & $62-82 \%$ & $65.2 \%$ & $61-84 \%$ & $66.5 \%$ \\
\hline
\end{tabular}

Table 5 exhibited the level of $w$ in different scenarios. As the value of $w$ was 14.11 
$\mathrm{g}_{\text {water }} / \mathrm{kg}_{\text {air }}$ for tunnel air, higher than that for supply air, which was $13.61 \mathrm{~g}_{\text {water }} / \mathrm{kg}_{\text {air, }}$, the results also indicated that increasing exhaust air volume was not a good solution under the design conditions because it would suck humid tunnel air into the platform. On the other hand, the industrial dehumidifier was proved more efficient when comparing the average value of $w$

\section{Table 5}

Comparison of $w\left(\mathrm{~g}_{\mathrm{water}} / \mathrm{kg}_{\mathrm{air}}\right)$ in different scenarios.

\begin{tabular}{l|ccccccccc}
\hline Location & \multicolumn{3}{|c}{ Air near the AGMs } & \multicolumn{3}{c}{ Air near the upper structure of PSDs } \\
& \multicolumn{2}{c}{ Side A } & \multicolumn{2}{c}{ Side C } & \multicolumn{2}{c}{ Side A } & \multicolumn{2}{c}{ Side C } \\
Scenarios & range & average & range & average & range & average & range & average \\
\hline Scenario 1 & $13.61-13.69$ & 13.65 & $13.62-13.69$ & 13.67 & $13.85-13.91$ & 13.86 & $13.85-13.91$ & 13.89 \\
Scenario 2 & $13.58-13.67$ & 13.63 & $13.61-13.72$ & 13.64 & $13.78-13.92$ & 13.88 & $13.85-13.96$ & 13.93 \\
Scenario 3 & $12.23-13.39$ & 12.58 & $12.18-13.01$ & 12.49 & $12.57-13.91$ & 12.95 & $12.11-13.92$ & 12.60 \\
\hline
\end{tabular}

\section{Conclusions}

Metro stations often have condensation issues due to the lack of effective moisture control, especially in the commissioning and initial operation phases. These issues would lead to negative influence on both IAQ and equipment operation. To justify the issues and provide solutions, this paper presents a holistic approach for assessing and controlling the moisture environment in metro stations. Firstly, the indoor environment of underground stations has been investigated through on-site measurements in Tianjin during the summer time. Then, a numerical model used for predicting the distribution of $\mathrm{RH}$ under different scenarios was established, with validation against measurements. Lastly, the effects of the two dehumidification solutions were numerical analyzed. According to the results, the following conclusions are drawn. 
(1) The on-site measurement showed that the air temperature in public areas changed within the range of $23{ }^{\circ} \mathrm{C}$ to $28{ }^{\circ} \mathrm{C}$ and the $\mathrm{RH}$ changed within the range of $30 \%$ to $90 \%$, respectively. The air temperature in the station was maintained relatively stable, but with significantly changing humidity. The temperature of the hall was higher than that of the platform, and the humidity of the hall was lower than that of the platform in most times of summer.

(2) For almost $30 \%$ of the testing time, the platform had RH levels defined as either "wet" or "very wet". Conversely, for approximately $11 \%$ of the overall test time, the RH in the hall fell within the range of "wet". The surface of the upper structure of PSDs had a higher risk of condensation than that of the interior wall in hall level, especially in early morning and rainy days. Thus, the platform is a key area for moisture control.

(3) The simulation results showed that no condensation in the station under the design conditions. In some areas, however, the RH would exceed $70 \%$. Increasing the exhaust air volume would decline the humidity in the hall but increase the air humidity near the exhaust inlets in the platform as the inhalation of more humid air from the tunnel. The effect of industrial dehumidifier was more significant and flexible than increasing exhaust air volume.

This study using both measurement and simulation methods to enhance moisture control in the public areas of underground stations has practical significance on protecting and ensuring the continuity of operation of metro networks. In future research, the cost evaluation and optimal placement of dehumidifiers, as well as the operation mode of ventilation systems, could be conducted to achieve global optimal control of the moisture 
level in public areas. Moreover, the moisture environment of technical or facility rooms

in metro stations will also be investigated.

\section{References}

1. China Association of Metros, 2019. Annul statistics and analysis of urban railway system in 2019 (In Chinese), www.camet.org.cn/tjxx/ (2020 (accessed 26 January 2021)).

2. Yu J, Kang Y and Zhai Z. Advances in research for underground buildings: Energy, thermal comfort and indoor air quality. Energy and Buildings 2020; 215. DOI: 10.1016/j.enbuild.2020.109916.

3. Ninikas K, Hytiris N, Emmanuel R, et al. Heat recovery from air in underground transport tunnels. Renewable Energy 2016; 96: 843-849. DOI: 10.1016/j.renene.2016.05.015.

4. Teodosiu R. Integrated moisture (including condensation) - Energy-airflow model within enclosures. Experimental validation. Building and Environment 2013; 61: 197-209. DOI: 10.1016/j.buildenv.2012.12.011.

5. Zhang H, Liu J, Li C, et al. Long-term investigation of moisture environment in underground civil air defence work. Indoor and Built Environment 2016; 26: 744-757. DOI: 10.1177/1420326x16637658.

6. $\quad \mathrm{lv} \mathrm{W}, \mathrm{Li}$ A, Ma J, et al. Relative importance of certain factors affecting the thermal environment in subway stations based on field and orthogonal experiments. Sustainable Cities and Society 2020; 56. DOI: 10.1016/j.scs.2020.102107.

7. Pan S, Liu Y, Xie L, et al. A thermal comfort field study on subway passengers during air-conditioning season in Beijing. Sustainable Cities and Society 2020; 61. DOI: 10.1016/j.scs.2020.102218.

8. Liu J, Wang Z, Shan P, et al. Investigation and low energy improvement of the thermal environment of work areas in the Qingdao Metro in winter. Building Services Engineering Research and Technology 2019; 41: 60-72. DOI: 10.1177/0143624419867198.

9. Wang Y, Li J and Li X. Subway simulation of CO 2 concentration during close mode operation. Sustainable Cities and Society 2017; 28: 201-208. DOI: 10.1016/j.scs.2016.09.007.

10. Wu L, Xia H, Wang X, et al. Indoor air quality and passenger thermal comfort in Beijing metro transfer stations. Transportation Research Part D: Transport and Environment 2020; 78. DOI: 10.1016/j.trd.2019.102217.

11. Yu Y, You S, Zhang H, et al. A review on available energy saving strategies for heating, ventilation and air conditioning in underground metro stations. Renewable and Sustainable Energy Reviews 2021; 141. DOI: 10.1016/j.rser.2021.110788.

12. Liu C, Li A, Yang C, et al. Simulating air distribution and occupants' thermal comfort of three ventilation schemes for subway platform. Building and Environment 2017; 125: 15-25. DOI: 10.1016/j.buildenv.2017.08.036.

13. Wen Y, Leng J, Yu F, et al. Integrated design for underground space environment control of subway stations with atriums using piston ventilation. Indoor and Built Environment 2020; 29: 1300-1315. DOI: $10.1177 / 1420326 \times 20941349$.

14. Wang L, Du Z, Zhang J, et al. Study on the thermal comfort characteristics under the vent with supplying air jets and cross-flows coupling in subway stations. Energy and Buildings 2016; 131: 113-122. DOI: 10.1016/j.enbuild.2016.09.012.

15. Zhang Y and Li X. Research on airflow and energy performance in PBD, PSD and PBD-PSDcombined environment control systems in subway. Sustainable Cities and Society 2018; 42: 434-443. DOI: 10.1016/j.scs.2018.04.032. 
16. Li G, Meng X, Zhang X, et al. An innovative ventilation system using piston wind for the thermal environment in Shanghai subway station. Journal of Building Engineering 2020; 32. DOI: 10.1016/j.jobe.2020.101276.

17. Zhang $\mathrm{H}$, Zhu $\mathrm{C}$, Zheng $\mathrm{W}$, et al. Experimental and numerical investigation of braking energy on thermal environment of underground subway station in China's northern severe cold regions. Energy 2016; 116: 880-893. DOI: 10.1016/j.energy.2016.10.029.

18. Kim M, Braatz RD, Kim JT, et al. Indoor air quality control for improving passenger health in subway platforms using an outdoor air quality dependent ventilation system. Building and Environment 2015; 92: 407-417. DOI: 10.1016/j.buildenv.2015.05.010.

19. Park JH, Son YS and Kim KH. A review of traditional and advanced technologies for the removal of particulate matter in subway systems. Indoor Air 2019; 29: 177-191. 2018/12/27. DOI: 10.1111/ina.12532. 20. Yuehua L. Rearch of dehumidify and air supply technology in platform public area of subway (In Chinese). Harbin Institute of Technology (Master thesis). 2013.

21. Hao X. The present situation research of thermal and moisture environment in Xi' an underground construction (In Chinese). Xi'an Polytechnic University (Master thesis). 2016.

22. Hui W. The Study of Dehumidification Solution in the Air-Conditioning of Subway No.1 in Nanjing (In Chinese). Contam Control Air-conditioning Technol 1, 46-52 2010.

23. Shi L, Zhang H, Li Z, et al. Analysis of moisture buffering effect of straw-based board in civil defence shelters by field measurements and numerical simulations. Building and Environment 2018; 143: 366-377. DOI: 10.1016/j.buildenv.2018.07.018.

24. Dawood T, Zhu Z and Zayed T. Computer Vision-Based Model for Moisture Marks Detection and Recognition in Subway Networks. Journal of Computing in Civil Engineering 2018; 32. DOI: 10.1061/(asce)cp.1943-5487.0000728.

25. Zhao S, Zhang DM and Huang HW. Deep learning-based image instance segmentation for moisture marks of shield tunnel lining. Tunnelling and Underground Space Technology 2020; 95. DOI: 10.1016/j.tust.2019.103156.

26. Zs A and Xla B. Sub-system energy model based on actual operation data for subway stations. Sustainable Cities and Society 2019; 52: 101835.

27. Subway environmental design handbook, Volume I :Principles and Applications, Second Edition, 1976. Washington, D. C.

28. Cengel YA and Boles MA. Thermodynamics: An Engineering Approach. Thermodynamics: An Engineering Approach, 2009.

29. Lawrence MG. The Relationship between Relative Humidity and the Dewpoint Temperature in Moist Air: A Simple Conversion and Applications. Bulletin of the American Meteorological Society 2005; 86: 225-234. DOI: 10.1175/bams-86-2-225.

30. You S, Li W, Ye T, et al. Study on moisture condensation on the interior surface of buildings in high humidity climate. Building and Environment 2017; 125: 39-48. DOI: 10.1016/j.buildenv.2017.08.041.

31. Tao Z, Xiaohua, L., Bowen, G. Design,operating status and research prospects of ventilation and air conditioning systems in underground railway stations (In Chinese). $H V \& A C 48,8-14.2018$.

32. Yingxin Z. Built environment (In Chinese). China Architecture \& Building Press, Beijing. 2010.

33. Yuan F-D and You S-J. CFD simulation and optimization of the ventilation for subway side-platform. Tunnelling and Underground Space Technology 2007; 22: 474-482. DOI: 10.1016/j.tust.2006.10.004.

34. Clarke JA. Fluid flow, in: Clarke, J.A. (Ed.), Energy Simulation in Building Design (Second Edition). Butterworth-Heinemann, Oxford, pp 126-156. 2001.5.

35. Code for design of metro (GB 50157-2013). China Architecture \& Building Press, Beijing. 2013. 
36. Xue $\mathrm{F}, \mathrm{Xu} \mathrm{C}$, Shen $\mathrm{W}$, et al. Ventilation in pumped storage power stations: Influence of dehumidifiers in an underground tunnel. Applied Thermal Engineering 2020; 172. DOI: 10.1016/j.applthermaleng.2020.115162. 


\section{List of Figures}

NO. $\quad$ Figure legends

Figure 1. Condensation on tunnel walls and platform doors in an underground station.

Figure 2. Schematic of underground station structure (half section).

Figure 3. Schematic of heat/moisture gain for the public areas of an underground station during commissioning.

Figure 4. The automatic gate machine and the motor of the PSD system.

Figure 5. Layout of the test points in the hall and platform.

Onsite measurements in the station: (a) and (d) installing the sensor; (b) and (e)

Figure 6. measuring device and wall surface temperature; (c) measuring velocity at openings; and (f) test point $\mathrm{T} 1$ settled in the tunnel.

Figure 7. Schematic diagram of the station.

Figure 8. (a) one of the access air temperature and $\mathrm{RH}$ profile and (b) tunnel air temperature and $\mathrm{RH}$ profile with the interval of $30 \mathrm{~s}$ in summer.

Figure 9. Boxplot of the (a) temperature and (b) RH at test points

Grid dependence study: (a) grids for the hall (H1-1805481 nodes, H2-2808759 nodes,

Figure 10. and H3-3011977 nodes) and (b) grids for the platform (P1-1085589 nodes, P21831356 nodes, and P3-2089446 nodes).

Figure 11. Station air temperature and RH at test points.

Figure 12. Frequency of the station's RH over the test period.

Figure 13. Comparison of the interior wall surface temperature and the hall air dew point temperature.

Figure 14. Comparison of the upper structure surface temperature and the platform air dew point temperature.

Figure 15. The RH distribution in the plane $\mathrm{Z}=1 \mathrm{~m}$ of the hall: (a) the designed ventilation condition (scenario 1), (b) solution 1 (scenario 2) and (c) solution 2 (scenario 3).

Figure 16. The RH distribution in the plane $\mathrm{Z}=2.5 \mathrm{~m}$ of the platform: (a) the designed ventilation condition (scenario 1), (b) solution 1 (scenario 2) and (c) solution 2 (scenario 3). 